\title{
Disparate understandings of the nature, purpose and practices of reflection in teacher education
}

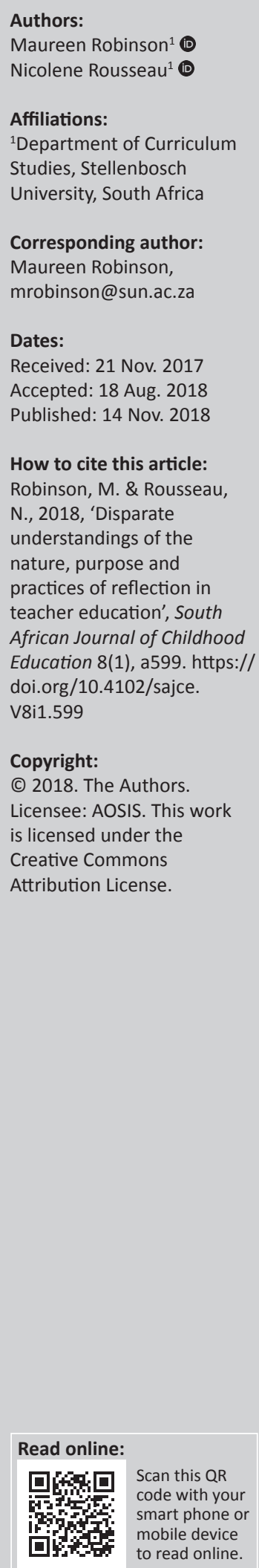

Background: The concept of reflection is much used in teacher education in many parts of the world, including in South African teacher education policy. However, the notion of reflection is often loosely defined, with differing understandings of its nature, purpose and curriculum implications.

Aim: This article explores how teacher educators and student teachers understood and implemented the notion of reflection in their teacher education programmes.

Setting: The research took place as a multisite case study at four South African universities offering the Bachelor of Education (Foundation Phase).

Methods: Interviews were conducted with 24 senior students and 8 teacher educators.

Results: The study revealed disparate views by both teacher educators and student teachers of the nature, purpose and practices of reflective practice and largely tacit understandings of the role of reflection in teacher education. For most interviewees, the emphasis of reflection lay within a technical rational approach of improving teaching rather than a critical approach of locating education within a wider social context. Against the background of the many challenges in South African schooling, we argue that critical reflection is a means to encourage student teachers to become more independent and socially committed teachers.

Conclusion: We present a case for the concept and practices of reflection to be more purposefully explored by teacher educators, thereby contributing towards continued agency and transformation in education.

\section{Introduction}

In this study we explore Foundation Phase teacher educators' and student teachers' understandings of the nature, purpose and practices of reflection in initial teacher education. It is our view, based on years of participation in the field, that many unanswered questions exist in South African teacher education about reflection and that the concept is underestimated in terms of both its complexity and its potential. Although reflection is named as one of the components of integrated and applied knowledge in the national qualifications policy framework for teacher education (Department of Higher Education (DHET) 2015), the concept is not defined beyond referring to reflection as one way of 'giving renewed emphasis to what is to be learnt and how it is to be learnt' (DHET 2015:9). Thus, this article explores the question: How do Foundation Phase teacher educators and student teachers at four South African universities understand and implement the notion of reflection in a Bachelor of Education programme?

Reflective practice is a much used concept in teacher education and there exists 'a plethora of literature on reflective teaching' (Fendler 2003:16). Drawing on international scholarship, we begin by outlining various traditions in reflection. We then argue the importance of one of these traditions - critical reflection - as a contribution to producing critical, independent and socially committed teachers, able to position themselves in relation to the inequalities of South African education (Beylefeld \& le Roux 2015). This is followed by an account of interviews with student teachers and teacher educators, where we highlight the disparate views that seem to exist on the concept, purposes and practices of reflection, both within and amongst student teachers and teacher educators.

Our argument for exploring reflection derives from a number of aspirations and challenges in South African education post-democracy. Five examples are cited here. The Education White Paper of 1997 emphasised that South African higher education institutions should be producing graduates with critical, analytical and problem-solving skills and competences 
(Department of Education 1997). The national Higher Education Transformation summit, held in 2015, reiterated the key role of higher education in South Africa in helping to build an open, democratic, post-apartheid society and an informed and socially aware citizenry (Council on Higher Education 2015). The Minimum Requirements for Teacher Education Qualifications (MRTEQ) (DHET 2015:10) refers to the need for students to reflect on lessons presented by themselves and others, learning both from theory and practice. The report of the National Education Evaluation \& Development Unit (NEEDU) (2013) cites the outcome of the Southern and Eastern Africa Consortium for Monitoring Educational Quality (SACMEQ) language test of 2007, where teachers did well on items requiring retrieval of information, but poorly on those items requiring the higher cognitive functions of inference, interpretation and evaluation (NEEDU 2013:25). Furthermore, this report argues the importance of learners developing skills of inferential and interpretive reasoning, in order to engage with 'why' and 'how' questions (NEEDU 2013:74). The very structured nature of the national school curriculum (Curriculum Assessment Policy Statement) has left limited time and space for teachers to reflect and implement innovative learning processes.

Against this background, the research set out to ask - What concepts and practices do teacher educators draw on in order to nurture and promote habits of reflection in their student teachers? And what are the experiences of student teachers in this regard?

\section{Conceptual orientations}

Over three decades ago, Van Manen had already identified three 'ways of knowing' in reflective practice: the technical, the practical or interpretive, and the critical (Van Manen 1977:225-226), with the latter emphasising long-term shifts in personal understandings, reflexivity and social agency. Similarly, Zeichner and Liston (2014) distinguish between four traditions from which one can look at reflection as a form of learning: a conservative (academic) tradition which stresses content and skills, a progressive (developmentalist and pragmatic) tradition stressing the needs of the child, a social justice tradition dealing with oppressive social forces such as race, gender and class and lastly a spiritual tradition, stressing significant life meaning. Yost, Sentner and ForlenzaBailey identify a first level of reflection as routine action 'guided by authority and experience' (2000:41), without an inclination to justify actions taken, and critical reflection as a higher level of thought processes where there is a conscious awareness, careful consideration of consequences and finally cognitive change. Finally, Korthagen (2001:53) identifies a number of 'functions' for reflection which vary from enabling teachers to analyse, evaluate and change their own practice to the appraisal of moral and ethical issues which include their own beliefs about good teaching.

A shift in the purpose of reflection from predominantly short-term, with the emphasis on knowing and doing, to long-term shifts in personal understandings, reflexivity and social agency is reflected in these various traditions and conceptual orientations, with the critical lens providing a framing within a paradigm of social justice, ethics and the greater good of society.

The complexity of the notion of reflection has also been highlighted in various studies exploring the practical and pedagogical implications of the concept. These include issues related to assessment, the relationship between process and product, and the scaffolding of critical reflective practice.

On the issue of assessment, Loughran (2006:129) argues that assessment is in opposition to what we try to achieve by reflection because the emphasis can shift so easily to a simple right and wrong approach. This dilemma, as will be shown later, was a factor that emerged clearly from the data of this study.

LaBoskey (as cited in Calderhead \& Gates 1993:30) cautions that there is a distinction between the 'common-sense' thinker only interested in quick fixes (product oriented) and the alert novice who wants to know why they are doing what they are doing (process oriented). Again, this is a tension reflected in our data.

Researchers have reported on the difficulty students experience specifically with critical reflective practice (Moore 2005). Yost et al. (2000) point to the need for 'a concerted and unified effort amongst teacher educators guided by structured curricula to promote critical reflection' (2000:46). Guided reflection has been argued (Nolan 2008) to offer the benefit of providing language and structures to scaffold reflective practices. Nolan recounts how significant his own focus group discussions were in enabling deeper levels of reflection by creating deliberate mapping opportunities to reflect critically on sensitive issues in an accepting environment of trust.

The above discussion leads to a reminder that teacher educators themselves need to consider when students should be expected to participate meaningfully in critical reflection and the students' own stage in the learning process, as 'a concern for personal survival' (Down \& Hogan 2000:6) is likely to predominate in the early part of their teacher education. McIntyre (1995:366) suggests that students first just focus on a critical stance towards ideas from different sources and only once they have enough experience will they benefit from reflecting on their own personal practice. Similarly, other South African research found that small group discussions amongst first-year pre-service teachers were only able to initiate in the students 'a shallow positioning of themselves in relation to the complex, socio-political issues that constitute our inequitable education system' (Beylefeld \& le Roux 2015:15).

The challenges involved in teaching and learning through critical reflective practice seem to demand of teacher educators 
an explicit reconsideration of their goals and practices. In the following section, we report on the findings of a study that explored how teacher educators and student teachers were responding to these challenges in the teacher education programmes (BEd Foundation Phase) of four South African universities.

\section{Research methods and design}

The investigation was conducted as a multisite case study at four universities. At the time of the study, all four universities were in the process of recurriculating their teacher education programmes in alignment with the new policy framework on teacher education (MRTEQ). Data were gathered through interviews with teacher educators and student teachers at each of the research sites, and documentary analysis of policies and course materials was carried out.

Twenty-one universities were involved in Foundation Phase teacher education in South Africa during 2013 (Green, Adendorff \& Mathebula 2014). Of these, four (universities A, B, C and D) were purposefully selected as the sample for the study. The criterion for selection was significant student enrolment in the 4-year Bachelor of Education Foundation Phase programme and a long-standing tradition of teacher education. Each interview took place on the premises of that particular university and lasted about $45 \mathrm{~min}$. Access to these universities was facilitated by the fact that the principal researcher was herself a lecturer in the same field and had regular contact with colleagues at these universities through a professional association. A contact person (lecturer) in the Foundation Phase programme at each university was asked to identify the informants who would be best placed to share insights and experiences.

Semi-structured interviews were conducted with two Foundation Phase teacher educators from each university: one who was closely involved in the policy-driven curriculum development which characterised teacher education in South Africa in the period 2011-2015 and an other who was involved in the teaching of one of the core methodology subjects of the Foundation Phase, namely Language, Mathematics or Life Skills, the latter encompassing a combination of the arts, sciences and Life Orientation for the Foundation Phase. All were also involved in the teaching experience programme where students have to do supervised teaching in Foundation Phase classrooms. All were women, with varying levels of lecturing experience.

Where the subject Professional Practice (also called Professional Studies in some universities) was offered, its course outline provided further insights into the links between teaching experience and theory. The subject includes topics like classroom management, administration and action research and is regarded as the bridge between university input and the classroom.

Interview questions to teacher educators focused on the role of reflection in the particular teacher education programme and included aspects such as the content, the purpose, the levels, the challenges and the products of reflection expected from the students. Most questions were open-ended to allow participants to frame their understandings in their own ways.

Focus group interviews were conducted with six final year BEd Foundation Phase students at universities A, B and D. At university $C$, third-year students were interviewed, as the final year students were away on teaching experience. Of 24 students interviewed, 23 were women. The majority of the students interviewed at university $C$ were Afrikaans speaking, whilst those at universities A, B and D were predominantly English speaking. Other than one black African student from university B, all the students interviewed would have been classified as white or of mixed race in the former South African dispensation. Whilst this demographic could be seen as a limitation of the study, it was illustrative of the skewed enrolment patterns in the Foundation Phase programme in South Africa at that time (Green et al. 2014:9).

Students were interviewed about the role of reflection in their training. The emphasis here was on their knowledge and perceptions of the concept of reflection, levels of reflective practice, their understanding of the purposes of reflection and the challenges experienced. All interviews were recorded and transcribed.

The models and classifications of Van Manen (1977) and Zeichner and Liston (2014) were used to gain insight into participants' conceptual framing and practical implementation of reflective practice. Thematic analysis was used to code, tabulate and categorise the patterns emerging from interviewees' expressed views and understandings. Patterns from the data were refined through a reduction process and used to interpret and analyse the findings within the central scholarly debates. In this sense, we opted for a blend between a deductive analysis, based on certain analytical framings, together with an inductive approach where the themes were linked to the emerging data.

BEd programme and course outlines were perused in order to establish the intended role of reflective practice. However, these were found to focus more on technical details such as credits, dates, etc., and as such were not used further in the analysis of the data.

The interview data provided insight into teacher educators' and student teachers' perspectives on the purposes for which reflective practice is and can be used in their teacher education programmes and how it is experienced. It also reflected the most dominant tradition(s) in which reflection is practised and the challenges experienced in the context of the four teacher education programmes.

To analyse the interviews, a matrix was developed in order to move between descriptive codes (what the interviewees said), analytic memos (how the findings related to the theory 
and to other data) and themes (broader categorisations). The emerging categories were then narrowed down to three dominant themes: disparate views of the conceptual nature and purposes (what $\mathcal{E}$ why) of reflective practice; disparate views of the practices (how) of reflective practice; and the largely tacit understandings of teacher educators and students of the role of reflective practice in teacher education. These themes are discussed in the next section.

\section{Ethical considerations}

Ethical clearance was received from the university, participation of all interviewees was voluntary and confidentiality was guaranteed.

\section{Results}

\section{Disparate views of the conceptual nature and purposes (what \& why) of reflective practice}

All the teacher educators in the study agreed that reflective practice is of great importance in teacher education; however, their understandings of the concept and purposes of reflective practice varied. Most agreed that reflective practice is a form of enquiry which leads to problem-solving or improvement of practice and that it is a core principle of their curriculum and regarded as a very important process in teaching and learning.

The teacher educators shared a predominantly interpretive understanding of reflective practice, as a means to go beyond comments such as 'the lesson was lovely'. For them, it was about encouraging depth of inquiry, thereby improving student teachers' understanding of teaching and learning. One teacher educator defined reflection in the following way:

It is a cyclical thing - to stand back and to re-visit in order to improve. The purpose of reflection is to know why you are doing what you are doing, to learn about yourself and your assumptions, to inquire about teaching and learning. These aspects are considered important because of the diversity in our classrooms. (University C, female, programme coordinator)

Despite prompting from the interviewer, no mention was made by any of the teacher educator participants of encouraging students to link their observations with theory or broadening their observations to include a critical lens on moral, ethical and social issues and the potential of critical reflection to motivate agency in this respect.

However, the student teachers had limited regard for the process of reflection, linking its importance only with a final product. Student focus groups shared a rather narrow understanding of reflective practice. For them, it was about describing what happened in the classroom and then focussing on what they did wrong - and to a lesser degree what they did right - 'what worked and what didn't work', an approach reminiscent of the technical-rational approach to reflection as outlined by various theorists (Korthagen 2001; Schön 1987; Zeichner 2014).
Although the student focus groups indicated early in the interviews that they understood the concept of reflection very well, they became more uncertain about it as the interview progressed. Two student focus groups indicated towards the end of the interview that they suspect they do not actually understand the real potential of reflective practice as a means to link theory and practice or to become a vehicle for agency. They admitted to not putting much effort into reflection 'unless a mark is given' and that they try to write what they think the teacher educator expects from them if they thought it might be assessed. One student indicated that he saw little purpose in reflective practice if it was not assessed. This view was not opposed by his fellow interviewees.

Students reported that they were expected to reflect on their teaching in journals, lesson reflections and post-lesson discussions; however, they indicated that they were unsure of what a good reflection should look like: 'We write what we think the lecturer wants, (University B, female, final year BEd student). Another student teacher said: 'We have found out that the lecturers want us to say what we can improve' (University A, male, final year BEd student). A general trend throughout the interviews was that the teacher educators were in agreement about most aspects, whilst the student teachers were equally in agreement about their perceptions. However, what was surprising was the extent to which student perceptions differed from those of their lecturers and the fact that neither of the two groups of participants seemed to realise the extent to which they had divergent views of reflective practice. One example of this was teacher educators' agreement that students should be able to use reflective practice well once they are qualified teachers whilst the students themselves identified it as a 'university thing' which is not done by teachers in the workplace 'since there is no time for reflection in school'. In the final analysis, this means that whilst the teacher educator participants saw reflective practice as an investment with long-term potential, student teachers perceived it as a short-term activity whilst at university.

None of the participants was aware of a structure in their curriculum providing continuous theoretical and practical support for reflective practice. There was also no significant evidence of using critical reflection to consider the real-life tensions of a broader South African society, or the African and global context.

Reflective practice is regarded in the scholarship as an important means of integrating theory and practice (Korthagen 2001; Zeichner \& Liston 2014); however, the majority of the teacher educators and none of the student participants referred specifically to this aspect. This was surprising because it was clear from their examples that most of the reflection that students did was done during school experience when they were expected to reflect on the lessons they had taught.

There was no evidence in the study that either teacher educators or students had separately or together deliberated 
on the different functions or purposes of reflective practice. There was also no evidence that the student teachers had been made aware of how these purposes relate to how reflective practice is used. As already indicated, student participants reported that their reflections consist mainly of reporting on so-called 'improvements' to their practice and are mainly about classroom management. Such examples could be considered to be within a technical orientation; however, a more nuanced view on this is provided by Hoy and Woolfolk (as cited in Korthagen 2001:47), who argue that technical competence can be seen as a precondition for reflection, to enable the student to develop both a starting competence and a growth competence.

\section{Disparate views of the practices (how) of reflective practice}

In spite of the importance that teacher educators and the qualifications framework for teacher education attached to reflective practice, none of the teacher educators who were interviewed could produce documentary evidence of a curriculum or timetable aimed explicitly at student teacher knowledge of the concept, use or development of reflection. Responses about how reflection is defined in their curricula were vague and general; only one university had provided some clarification of the concept in its Teaching Practice assessment rubric. Reflection on teaching was located here on a continuum from 'not yet coping' (does not acknowledge problems with lesson even when pointed out) to 'thoughtful, insightful' (reflects during lesson and changes tack if necessary; in-depth reflection follows).

The teacher educators as well as the students at the four universities were in agreement that reflective practice is particularly important in the school-based component of their programme. Some examples were given of how reflective practice was built into the design and teaching of methodology subjects; these on the whole referred to technical reflective practices of identifying and correcting practical aspects of teaching. One teacher educator spoke about working from the 'self' to the 'general', whilst another mentioned that students are encouraged to write about their emotions in relation to teaching incidents. Two further examples were 'relating discipline issues to their discipline issues in the school' and 'how to adapt resources for use in under-resourced schools'. No examples were given of critical reflection, although one or two examples referred to an interpretive approach with greater understanding of classroom practices as purpose. The teacher educators (all of whom were involved in teaching methodology subjects) were not able to give examples of reflective teaching from subjects outside of those that focused on pedagogical learning, but one student focus group referred to 'once talking about' socio-political aspects during an education lecture.

Several inconsistencies were noted in the analyses: In spite of the fact that most of the teacher educators flagged reflective practice as used by all lecturers and integrated in all subjects, it was not taught as a discrete topic at any of the four sites. Students' examples of critical reflection showed that they were under the impression that 'things that don't work' are examples of 'critical' reflective practice. Whilst the students reported that reflective practice is prominent in most subjects, examples mentioned by both teacher educators and students focused predominantly on teaching experience and to a lesser extent on the methodology subjects and the practical subjects such as Art and Music.

Students also disagreed with their lecturers that reflective practice focuses on both short- and long-term benefits. All student focus groups indicated that their reflective practice focuses mostly on short-term interventions to improve their immediate practice. One student explained:

Perhaps we should be required just to reflect on our crit. lessons [lessons evaluated by teacher educators]. I am not actually sure if I reflect in the right way since I have never had feedback on my reflections. In fact, initially we thought it was just nonsense but now we understand the purpose. (University D, female, final year BEd student)

The comment was followed up by a discussion which revealed that the purpose was understood to 'correct' methodological practices in the classroom. Some resistance to engaging in deeper levels of reflection was highlighted in the following student comment:

The ability to reflect deeper than actually just saying what's wrong and what's right, that's hard for me personally ... if there's something wrong then you can fix it. You don't want to look deeper... Just Google it (laughter). (University D, female, final year BEd student)

A further observation was the tension between seeing reflection as process or reflection as product. Although all four student focus groups indicated that they understand that reflection is important, they could not 'see the point of it' unless the product was assessed. Therefore, the importance was for them not in becoming adept at using the process of reflection effectively and purposefully, but rather in the mark they get for it.

Another complexity was that of developing a language of reflection. Both students and teacher educators reported that many students find the language of reflection challenging, with students who are studying through the medium of a language other than their home language experiencing additional challenges. Zeichner and Liston (2014:7) write that reflection is in reality a multilayered and complex concept and therefore requires a language which reflects its subtle differences and many different purposes. The complexity of language is perhaps even more characteristic of the language of critical reflection because of the sensitivities involved another reason why the fostering of reflective processes needs to be planned and executed purposefully.

A further aspect that may contribute to the complexity of critical reflective processes is the need to question one's own personal assumptions and beliefs, especially in the 
presence of peers. At one of the universities, the teacher educators were convinced that reflecting on personal assumptions and bias would not be a problem for their students, yet the student participants at this university (as at the other three sites) indicated that they never reflect on their own assumptions, beliefs and bias, 'except for some cultural stuff in Education'. At another university, a student explained that 'you don't want to hurt each other', (University B, female, final year BEd student), presumably commenting on reflecting on each other's teaching.

\section{The largely tacit understandings of the role of reflective practice in teacher education}

The findings of this study suggest a number of tacit assumptions amongst staff and students regarding reflective practice and the role of both teacher educators and their students in fostering this approach. At the beginning of each interview, the participants in our study were without exception confident about their understanding of reflective practice and their interpretations and implementation thereof. Yet most of the interpretations proved to be vague and evidence in support of the views of the participants was lacking. Student participants in particular were unaware of the complexities involved or the far-reaching potential of reflection for educational practices.

Lecturers assumed that all staff are knowledgeable about reflective practice and use it extensively. As one put it: 'It is embedded into our curricula' (University A, female, teacher educator involved in curriculum planning), although she admitted, 'it might be challenging to operationalise reflection in the enactment of the curriculum'. At another university, a teacher educator followed up her comment that all staff use reflective practice by saying that she was not actually sure if others use it 'but people speak so often about it, it might be a principle written down somewhere in the curriculum' (university B, female, teacher educator). Yet teacher educators did not seem to know of any specific examples of reflective practice being used other than in their own subjects or during teaching experience. Teacher educators also assumed that students understand the importance of reflective practice, why it is often not used for marks and that it is a tool for lifelong learning at both personal and collaborative levels. One of the teacher educators indicated that identifying reasons for critical incidents in teaching and learning and linking it to contextual challenges' should be the most important reflective quality for a final year BEd student (University C, female, teacher educator involved in a methodology subject and teaching experience). However, when probed, neither the students at that university nor any other student focus group in the sample was familiar with the term 'critical incident'. A further anomaly was that teaching experience was pointed out as the area where reflection was used most often, yet both teacher educators and students indicated that teachers do not use reflective practice.

In spite of the teacher educators assuming that the students use reflection in, on and for action (Schön 1987), the students at three universities seemed unsure about the difference between these three purposes. The pattern observed from the student focus group responses was that reflection was viewed as largely a routine action - something the teacher educators expected from their students for every lesson taught. They were unsure of what a good reflection entails, yet their perception was that it is quite easy to reflect. Their emphasis was on the product - which could be a journal or a reflection following on a particular lesson and its assessment - rather than on the process of reflection which supports learning. None of the student teacher participants could think of examples of having done critical reflections in the sense of a socio-critical perspective or of having done reflections focussing on contextual and situational problems. They did not see it as particularly complex, although one or two student focus groups referred vaguely to 'critical' reflection as more difficult.

Teacher educators were obviously more familiar with the terminology and although they were convinced that reflective practice is important for teacher education, the examples referred mostly to improved strategies. One lecturer commented that her postgraduate students were more familiar with reflective practice and specifically critical reflection. The one thing student teachers were in agreement about was that they were overwhelmed by the number of reflections they have to do: 'done too often with little to reflect on except if there is a problem.' Another student focus group said: 'We are tired of reflections, there are simply too many' (university B, final year BEd students).

The student participants from the four universities were in agreement that reflective practice is important but their understanding of its potential as a means towards more meaningful long-term educational practices was limited. They were not familiar with processes of using reflective practice to interrogate personal or theoretical understandings. The examples mentioned were predominantly limited to teaching experience, but did not highlight context as a significant aspect. The value of reflective practice seemed to reside in the mark allocated and critical reflection seemed to be interpreted simply as 'being critical'. Only one group of student participants had been referred to a scholarly discussion about reflective practice. None of the groups could report on lecturer input and discussion on reflective practice as a concept.

An overriding pattern was the tacit understandings of reflective practice amongst the participants. Teacher educators assumed their fellow educators' and students' understandings of the concept to be similar to their own. Students assumed that their interpretations of the concept and its functions were similar to those of their educators. However, they did not seem to have shared with their educators that they were overwhelmed by the number of reflections and often just wrote what they thought the teacher educator would want to see.

Student participants in every focus group indicated towards the end of their interviews that they suspected they still have 
lots to learn about reflective practice. The majority of teacher educator participants felt that their faculties needed to reconsider the role of reflective practice in their curriculum.

\section{Discussion}

Zeichner and Liston (2014:4) have referred to reflection as the 'bandwagon' of teaching. Many of the challenges which became visible in this research reflect similar concerns about vague and somewhat narrow interpretations of the concept of reflection and the implications for practice. The findings of this research, for example, revealed the disparity between students' and teacher educators' notions of the purpose and meaning of reflective practice in education. Whilst each group seemed sure that there was mutual understanding of the concept, this was not the case. Students' and teacher educators' perceptions about the concept of reflective practice and its potential value for education varied.

Russell (2014:174) refers to 'the gap between ... espoused theories $\ldots$ and $\ldots$ theories-in-use (observed actions)' of teacher educators themselves. Although there seemed to be tacit agreement amongst the teacher educators that reflective practice is done by all, that their understanding is similar and that there must be faculty documentation to support this, colleagues seem to not have engaged with each other at either a theoretical or pedagogical level. The teacher educator participants all indicated confidently that reflection is used throughout the faculty but could hardly mention any examples except their own.

It was interesting to note that, in a context like South Africa, where student teachers have a great responsibility to become change agents within the overall purpose of improving the quality of education for all, there were few signs that critical reflective practice was encouraged or theorised in the teacher education programmes investigated. Rather, the study revealed that the function of 'improving' teaching at predominantly a technical rational level, or sometimes an interpretive level, was foregrounded. Missing was an overt sense of helping prospective teachers to come to terms with 'a wide array of things about learning, social and cultural contexts, teaching and be able to enact these understandings in complex classrooms serving increasingly diverse students' (Darling-Hammond 2006:3).

Somewhat disturbing were some of the student participants' outspoken comments about 'giving the lecturers what they want' and questioning the value of reflective practice unless assessed. Our own view is that whilst the product might be a reflection as part of a lesson plan, a journal inscription or a reflective essay, its growth value is not so much in the product, but in the process. Therefore, it lends itself better to formative assessment (if assessment is absolutely necessary) than summative assessment. Processes are, of course, not easy to assess. As Van Manen puts it: 'it is easier to teach informational knowledge and concepts than it is to effect... embodied understandings which will resonate in relations with others, the world around us and our actions' (2007:22).
Reflection has been argued as a way of bridging the gap between theory and practice (Frick, Carl \& Beets 2010). Yet the findings of this study showed that this potential means was under-theorised by the participant faculties. A teacher educator commented that students struggle to use theories as lenses: 'Students give one-dimensional answers to questions re shared space between theory and practice and miss out on the complexity of teaching.'

On the whole, neither student teachers nor teacher educators seemed to be sure about the purposes towards which they wanted to use reflective practice and how these purposes aligned with the way in which they use it. One student commented: '(I) did not know what was expected at first ... (but) towards the end we realised it is about learning.' Therefore, a key question is towards what purposes teacher educators encourage reflective practice. Many South African universities and faculties within universities have developed their own sets of graduate attributes; the question then becomes to what extent these attributes are embedded in their programmes. For example, if reflexivity is an expressed graduate attribute, one would expect a faculty to engage deeply with the concept and its purposes, debating what educators can expect their students to reflect on and how the process of reflection can be encouraged.

Boud and Walker note that critical reflective practice is 'highly context-specific' (1998:191) and the social and cultural context has a powerful influence over the way reflective practice is carried out. The lack of evidence in this study of reflecting collaboratively on socio-political issues might be a consequence of student resistance to talking about more personal aspects such as race and class, personal beliefs and contextual sensitivities. An anomaly then: there is a particular need for critical reflective processes in the teacher education programmes of a country like South Africa with its fractured history; yet it is this very challenge and the tensions caused by it which may contribute to student teachers' resistance to engaging in critical reflection on contentious issues.

\section{Conclusion}

South Africa has a dearth of research on entire programmes related to teacher education for the Foundation Phase (Du Plooy et al. 2016), a situation that is being addressed as more contributions to research on Foundation Phase teacher education comes to the fore, particularly through the establishment of the South African Journal of Childhood Education (Baxen \& Botha 2016). As part of building this research agenda, this study explored teacher educators' and student teachers' understandings of the notion of reflection at four universities in South Africa. The results showed that the teacher educators and student teachers in this particular sample had very different understandings of the nature, purposes and practices of reflection, and largely tacit understandings of the role of reflective practice.

The study was conducted at only 4 of the 21 universities in South Africa offering a Bachelor of Education in Foundation 
Phase at that time (Green et al. 2014:4) and generalisations from the findings must therefore be treated with caution. A potential limitation of the study was the fact that all four of the universities were in the process of redesigning their Foundation Phase curriculum, such that documentation was not always accessible or finalised. Nevertheless, we conclude with some general comments emerging from the findings, for further consideration by others.

We have argued that critical reflection has the potential to give student teachers the means to develop confidence in their own ability to constantly seek creative solutions to the many challenges that face them as novice teachers. All countries, including South Africa, require teachers who are able to bring about transformative learning in an openminded and thoughtful way. How then to address these challenges towards promoting reflective practice as a means to educate student teachers to become change agents within the South African context?

As teacher educators ourselves, some ongoing and as yet unanswered questions are stimulated by our own reflections on the findings of the study. Russell (2014:175), for example, mentions a challenge that may also hold true in the South African context: Students may have acquired many habits of teaching from their own school teachers. In the South African context, the school curriculum has become very prescriptive, and thus does not implicitly encourage an inquiry stance. How this impacts on student teachers' own approach to learning is a topic that is worthy of further investigation.

Against the background of the educational inequities in South Africa, it makes sense for education faculties to ensure that reflective practice is used to interrogate contested areas in wider society. However, the question is whether the social, political and ethical drivers of critical reflection form part of the theoretical frameworks that drive teacher education curricula. Such an orientation can provide a means to individually and collaboratively interrogate practices and beliefs, theorising and acting towards a practical wisdom for the greater good of society. Should there be faculty agreement and buy-in on the potential of critical reflective practice to address some of the challenges and tensions prevalent in education, faculties should look towards a coherent framework for pursuing such a purpose, as well as driving an ongoing discourse around the complexities and challenges characteristic of critical reflection.

We have argued that critical reflective practice should be more purposefully explored in teacher education. The challenge lies in the often vague interpretations amongst teacher educators of the epistemology of reflection and the variety of different processes, purposes, influences and foci associated with it - a challenge reiterated in the international scholarship on critical reflective practice.

By including emotional, spiritual, moral, ethical and political aspects of teaching, reflective practice has the potential to contribute to a more socially responsive teacher education programme. The role of critical reflection should be reconsidered for its potential to assist in reframing assumed realities and opening up pathways for new deliberations in education. Teacher educators like ourselves, we would argue, need to collaboratively and through dialogue contribute to reflective practice frameworks, thereby working towards continued agency and transformation in teacher education.

\section{Acknowledgements}

This study was funded in part by the 'Strengthening Foundation Phase Teacher Education Programme', a component of the European Union-South Africa Primary Education Policy Support Programme.

\section{Competing interests}

The authors declare that they have no financial or personal relationships that may have inappropriately influenced them in writing this article.

\section{Authors' contributions}

The study was conceptualised by both N.R. and M.R. N.R. collected and analysed the data, with M.R. as the adviser. The article is based on the PhD of Dr N. Rousseau, with Prof. M. Robinson as supervisor. The article was co-written and edited by both authors.

\section{References}

Baxen, J. \& Botha, L., 2016, 'Establishing a research agenda for foundation phase initial teacher education: A systematic review (1994-2014)', South African Journal of Education 36(3), 1-15. https://doi.org/10.15700/saje.v36n3a1263

Beylefeld, A. \& le Roux, A., 2015, 'Guided group reflections of first-year pre-service teachers: Moving beyond the rhetoric of "go and reflect"', Perspectives in Education 33(3), 1-19.

Boud, D. \& Walker, D., 1998, 'Promoting reflection in professional courses: The challenge of context', Studies in Higher Education 23(2), 191-207. https://doi.org/ 10.1080/03075079812331380384

Calderhead, J. \& Gates, P., 1993, Conceptualizing reflection in teacher development, The Falmer Press, London.

Council on Higher Education, 2015, Transformation in higher education, Discussion paper prepared for the second national Higher Education Transformation Summit, Second Higher Education Transformation Summit, 15-17th October.

Darling-Hammond, L., 2006, 'Constructing 21st century teacher education', Journal of Teacher Education 57(10), 1-15.

Department of Education (DoE), 1997, Education white paper 3. A programme for the transformation of higher education, Department of Education, Pretoria.

Department of Higher Education (DHET), 2015, Revised policy on the minimum requirements for teacher education qualifications (MRTEQ), Department of Higher Education, Pretoria.

Down, B. \& Hogan, C., 2000, 'Critical reflective practice and workplace learning Impediments and possibilities in teacher education', Australian Journal of Teacher Education 25(2). https://doi.org/10.1080/03075079812331380384

Du Plooy, L., Zilindile, M., Desai, Z., de Wet, B., Holtman, L., Julie, C. et al., 2016, 'Searching for research results to inform the design of an initial professional teacher education programme for the foundation phase: A systematic review', South African Journal of Childhood Education 6(1), a285

Fendler, L., 2003, 'Teacher reflection in a hall of mirrors: Historical influences and political reverberations', Educational Researcher 32(3),16-25. https://doi.org/ 10.3102/0013189X032003016

Frick, L., Carl, A. \& Beets, P., 2010, 'Reflection as learning about the self in context: Mentoring as catalyst for reflective development in pre-service teachers', South African Journal of Education 30(3), 421-437. https://doi.org/10.15700/saje. v30n3a363

Green, W., Adendorff, M. \& Mathebula, B., 2014, “"Minding the gap?” A national foundation phase teacher supply and demand analysis: $2012-2020^{\prime}$, South African Journal of Childhood Education 4(2), 1-23. https://doi.org/10.4102/sajce. v4i3.222 
Korthagen, F., 2001, Linking practice and theory. The pedagogy of realistic teacher education, Lawrence Erlbaum Associates, Inc, Mahwah, NJ.

Loughran, J., 2006, Developing a pedagogy of teacher education: Understanding teaching and learning about teaching, Routledge, New York.

McIntyre, D., 1995, 'Teacher education as practical theorizing: A response to Paul Hirst', British Journal of Educational Studies 43(4), 365-383. https://doi.org/10.10 80/00071005.1995.9974045

Moore, J., 2005, 'Is higher education ready for transformative learning? A question explored in the study of sustainability', Journal of Transformative Education 3(1) 76-91. https://doi.org/10.1177/1541344604270862

National Education Evaluation and Development Unit (NEEDU), 2013, The state of literacy teaching and learning in the foundation phase, National Report 2012, Pretoria.

Nolan, A., 2008, 'Encouraging the reflection process in undergraduate teachers using guided reflection', Australian Journal of Early Childhood 33(1), 31-41.
Russell, T., 2014, 'Paradigmatic changes in teacher education: The perils, pitfalls, and unrealized promise of the reflective practitioner', in R. Bruno-Jofré \& J.S. Johnson (eds.), Teacher education in a transnational world, pp. 158-176, University of Toronto Press, Toronto.

Schön, D., 1987, Educating the reflective practitioner, Jossey-Bass Publishers, San Francisco, CA.

Van Manen, M., 1977, 'Linking ways of knowing with ways of being practical', Curriculum Inquiry 6(3), 205-228. https://doi.org/10.1080/03626784.1977.11075533

Van Manen, M., 2007, 'Phenomenology of practice', Phenomenology and Practice $1(1), 11-30$

Yost, D., Sentner, S. \& Forlenza-Bailey, A., 2000, 'An examination of the construct of critical reflection: Implications for teacher education programming in the 21st century', Journal of Teacher Education 51(1), 39-49. https://doi.org/10.1177/ 002248710005100105

Zeichner, K. \& Liston, D., 2014, Reflective teaching: An introduction, 2nd edn., Routledge, New York. 